\title{
Safe Laparoscopic Cholecystectomy: Adoption of Universal Culture of Safety in Cholecystectomy
}

Eslam Taha Ghalwash

Departments of General Surgery, Faculty of Medicine, Al-Azhar University Cairo, Egypt

Corresponding author: Eslam Taha Ghalwash,E mail: ghalwash2006@gmail.com, Mobile phone: 01006784958

\begin{abstract} were excluded. complications. included male sex, leukocytic count, ALT and AST.

\section{BACKGROUND}

Laparoscopic cholecystectomy (LC) since its beginning in 1987, has dramatically substituted conservative open cholecystectomy. LC has been quickly the golden standard for repetitive gall bladder removals. Managements of biliary tract disorders has progressed from being a key operation to a comparatively safer and tolerable day care technique nowadays, presenting early resume to full activities ${ }^{(1)}$.

It reduces postoperative pains and ileus, permits faster oral intakes, shortens hospitalization and develops early return to usual activities and progresses cosmesis. ${ }^{(2)}$

Conversions to open cholecystectomy are not failures or complications, but a try to prevent side-effects. It can be supportive to determine the danger of conversions early. This can permit cases to have satisfactory psychological preparations, to be better ready for operation and to plot their convalescences ${ }^{(3)}$.

Repetitive general surgical techniques, involving laparoscopic appendectomy and LC have accompanying perioperative death rate of less than $1 \%$, leaving death a hard parameter to evaluate patients outcome ${ }^{(4)}$.

Morbidities, definitely advance of postoperative sideeffects, may be a more beneficial way to assess outcome thereafter common operations. Moreover, inspecting whether hospital and/or surgeon volume influences the outcomes for common operations would be a beneficial accumulation to our existing sympathetic of the interplay among volume and outcomes ${ }^{(5)}$.
\end{abstract}

Background: Laparoscopic cholecystectomy (LC) has been the favored technique for treating symptomatic cholelithiasis. LC has several benefits over the normal open cholecystectomy: negligible traumas, reduced pains, shorter hospitalization, acceptable cosmetic outcomes, rapid recovery, and back to work.

Aim and objectives: The aim of this study was to identify the predictors of safe LC.

Patients and methods: This prospective study was performed among 500 patients underwent LC who was attending to Al-Hussein Hospital, Al-Azhar University from January 2019 to June 2021. Cases with cholecystitis either acute or chronic, patients with age equal or more than 18 years old, and both sexes were included. While patients with age lower than 18 years old, patients with common bile duct (CBD) stone, pregnancy or patients with bleeding tendency history

Results: Upon assessing factors associated with postoperative complications of laparoscopic cholecystectomy, the male gender was statistically significantly correlated with complications while a non-significant change was found among complications and other sociodemographic variables. A significant association was found among WBCs, total bilirubin, ALT, AST, and complications while a non-significant association was found among gall bladder thickness and

Conclusion: In conclusion, this study evaluated the parameters that expect the complications in LC. Patient factors

Keywords: Complications, Laparoscopic cholecystectomy, Predictors, Safe laparoscopic cholecystectomy

This work aimed to recognize the prognosticators of safe LC.

\section{PATIENTS AND METHODS}

This prospective research was performed among 500 cases feeling LC who were attending to Al-Hussein Hospital, Al- Azhar University from January 2019 to June 2021.

Inclusion criteria: Patients with cholecystitis either acute or chronic, patients with age equal or more than 18 years old and both sexes were included.

Exclusion criteria: Patients with age lower than 18 years old and pregnancy or patients with bleeding tendency history.

The demographic data and preoperative information of the cases who needed laparoscopic cholecystectomy were investigated. The parameters analyzed were age, sex, BMI. Physical examination and preoperative lab were done. Ultrasonography, computed tomography and magnetic resonance cholangiopancreatography (MRCP) were done.

Formerly validated main complications counting acute myocardial infarctions, pulmonic compromise, postoperative infections, deep vein thrombosis, pulmonic embolism, haemorrhage, and re-operation were evaluated.

\section{Ethical approval:}

The Ethics Committee of the Faculty of Medicine, Al-Azhar University approved the study protocol 
and all patients gave a written consent for participation in this study. This work has been carried out in accordance with The Code of Ethics of the World Medical Association (Declaration of Helsinki) for studies involving humans.

\section{Statistical analysis}

Statistical analysis of the collected data has been performed via SPSS-26. Data have been examined for normal distributions by the Shapiro Wilk testing. Qualitative data has been introduced as frequency and percentage. Quantitative data has been introduced as mean and SD. Logistic regression was used to detect factors affecting conversion rate. Results were considered significant at $\mathrm{P}$-value $<0.05$.

\section{RESULTS}

The basic data of the participants are shown in table 1 .

Table 1: Basic data of the patients

\begin{tabular}{|l|l|}
\hline Variables & $\mathbf{N}=\mathbf{5 0 0}$ \\
\hline $\begin{array}{l}\text { Age (years), Mean } \pm \\
\text { SD }\end{array}$ & $42.5 \pm 15.7$ \\
\hline Male n (\%) & $21(42)$ \\
\hline Smokers n/day (\%) & $17(34)$ \\
\hline BMI, Mean \pm SD & $25.4 \pm 6.1$ \\
\hline
\end{tabular}

The results of physical examination, and investigations are shown in table 2 .

Table 2: Physical examination and investigation of the participants $(n=500)$

\begin{tabular}{|c|c|}
\hline Variables & Mean \pm SD or $n(\%)$ \\
\hline Heart rate (beat/min) & $78.6 \pm 11.4$ \\
\hline $\begin{array}{l}\text { Systolic blood pressure } \\
(\mathrm{mm} \mathrm{Hg})\end{array}$ & $115.7 \pm 12.3$ \\
\hline $\begin{array}{l}\text { Diastolic blood pressure } \\
(\mathrm{mm} \mathrm{Hg})\end{array}$ & $75.9 \pm 14.7$ \\
\hline $\begin{array}{ll}\begin{array}{l}\text { Respiratory } \\
\text { (breath/min) }\end{array} & \text { rate } \\
\end{array}$ & $14.8 \pm 2.5$ \\
\hline Temperature $\left({ }^{\circ} \mathbf{C}\right)$ & $37.1 \pm 0.4$ \\
\hline $\begin{array}{l}\text { Gall bladder thickness } \\
(\mathrm{mm})\end{array}$ & $4.6 \pm 0.7$ \\
\hline Peri-cholecystic fluid (n) & $120(24)$ \\
\hline Murphy sign positive (n) & $340(68)$ \\
\hline $\operatorname{ALT}(\mathbf{U} / \mathbf{L})$ & $63.1 \pm 11.3$ \\
\hline $\operatorname{AST}(\mathbf{U} / \mathbf{L})$ & $25.1 \pm 5.4$ \\
\hline GGT (IU/L) & $18.8 \pm 4.5$ \\
\hline $\begin{array}{l}\text { Serum } \\
(\text { IU/L) }\end{array}$ & $38.4 \pm 7.6$ \\
\hline $\operatorname{ALP}(I U / L)$ & $69.5 \pm 13.1$ \\
\hline Albumin (g/dl) & $33.2 \pm 4.3$ \\
\hline Total bilirubin $(\mathrm{mmol} / \mathrm{L})$ & $12.9 \pm 3.3$ \\
\hline WBCs $\left(* 10^{9}\right)$ & $5.5 \pm 1.4$ \\
\hline $\begin{array}{l}\text { Random blood sugar } \\
(\mathrm{mg} / \mathrm{dl})\end{array}$ & $120.7 \pm 15.3$ \\
\hline
\end{tabular}

\begin{tabular}{|l|l|}
\hline $\begin{array}{l}\text { Blood urea nitrogen } \\
\text { (mg/dl) }\end{array}$ & $8.7 \pm 2.1$ \\
\hline Serum creatinine (mg/dl) & $1.1 \pm 0.2$ \\
\hline
\end{tabular}

Nausea and vomiting were the most common postoperative complications (Table 3 ).

Table 3: Main postoperative complications of laparoscopic cholecystectomy among the participants $(\mathbf{n}=500)$

\begin{tabular}{|l|l|}
\hline Variables & $\mathbf{N}(\%)$ \\
\hline Postoperative infection & $20(4)$ \\
\hline Retained CBD stones & $10(2)$ \\
\hline Trocar-site bleeding & $20(4)$ \\
\hline Pulmonary embolism & $2(0.4)$ \\
\hline $\begin{array}{l}\text { Deep venous thrombosis } \\
\text { (DVT) }\end{array}$ & $3(0.6)$ \\
\hline Nausea/vomiting & $40(8)$ \\
\hline $\begin{array}{l}\text { MI } \\
\text { Infarction) }\end{array}$ & $10(2)$ \\
\hline Conversion, & $12(2.4)$ \\
\hline
\end{tabular}

Upon assessing factors associated with postoperative complications of laparoscopic cholecystectomy, the male gender was statistically significantly correlated with complications. A significant association was found among WBCs, total bilirubin, ALT, AST (Table 4).

Table 4: Factors associated with safe laparoscopic cholecystectomy among the participants $(n=500)$

\begin{tabular}{|l|l|l|}
\hline Variables & Odds ratio & p value \\
\hline Age & 0.16 & 0.152 \\
\hline Male gender & 1.19 & $\mathbf{0 . 0 0 2} *$ \\
\hline BMI & 2.13 & 0.541 \\
\hline Smoking & 1.27 & 0.411 \\
\hline $\begin{array}{l}\text { Gall bladder } \\
\text { thickness }\end{array}$ & 1.41 & 0.114 \\
\hline WBCs & 2.17 & $\mathbf{0 . 0 2 2}^{*}$ \\
\hline Total bilirubin & 2.10 & $\mathbf{0 . 0 1 1} *$ \\
\hline ALT & 3.12 & $<\mathbf{0 . 0 0 1}^{*}$ \\
\hline AST & 2.83 & $<\mathbf{0 . 0 0 1}^{*}$ \\
\hline
\end{tabular}

*p is significant

\section{DISCUSSION}

Presently, laparoscopic cholecystectomy is used widely as a standard procedure for benign gall bladder diseases which need cholecystectomy. LC decrease postoperative pains, allow early oral intakes, shorten hospitalization, faster back to ordinary activities, and progresses cosmoses over open operation ${ }^{(6)}$.

Cholecystectomy is one of the most common abdominal surgical procedures today, with a total of 150-200 operations per 100K populations in European Union and the USA yearly, of which over $80 \%$ is performed laparoscopically ${ }^{(7)}$.

A number of absolute or comparative contraindications were specified regarding to LC. Preceding upper abdomen operation was recorded as 
one of them owing to adhesion formations, which results in bowel or other abdominal constructions to adhere to the superficial of the abdomen wall ${ }^{(1)}$.

The general usage of the laparoscopic method to accomplish cholecystectomy has progressively improved from 0\% in 1987 to $93 \%$ in 2005 . The quick adoptions and acceptances of laparoscopy as the method of selection for cholecystectomy was ascribed to shorter hospitalization, reduced case illness, quicker recover to routine activities, and better overall cases satisfactions (2). LC is presently the golden standard in surgical managements for the mainstream of gallbladder diseases, with $>80 \%$ of cholecystectomies accomplished laparoscopically in the USA ${ }^{(8)}$. LC has been the favored technique for the treating the symptomatic cholelithiasis. LC has several benefits over the ordinary open cholecystectomy: negligible traumas, reduced pains, briefer hospitalization, acceptable cosmetic outcomes, rapid recoveries, and back to work ${ }^{(9)}$.

Nevertheless, for many causes there is a finite risk of conversions to open cholecystectomy in some cases. The commonest cause for conversion is the incapability to appropriately recognize the anatomy of the Calot's triangle as a consequence of inflammations in the zone round the gall bladder ${ }^{(4)}$.

This prospective research was performed among 500 cases underwent LC. This work aimed to identify the predictors of safe LC.

In the current study, regarding complications, there were $4 \%$ had wound infection, $2 \%$ had retained CBD stones, 4\% had Trocar-site bleeding, $0.4 \%$ had pulmonary embolism, $0.6 \%$ had DVT, $8 \%$ had nausea and vomiting and $2 \%$ had MI. The rate of conversion was $2.4 \%$ among the participants.

Our results were supported by Murphy and his colleagues, which enrolled a big national database to investigate the danger of main postoperative complications of LC. They found that general postoperative complications rate for cases underwent LC was $6.8 \%$ ( $n=75414$ patients). The commonest complications comprised gastro-intestinal haemorrhage $3.5 \%$ (39,021 cases), pulmonic compromise 1.3\%, $(\mathrm{n}=13780)$, perforation/laceration $0.5 \%, \quad(\mathrm{n}=5320)$, infections $0.5 \%(\mathrm{n}=5,198)$, and deaths $0.5 \%,(\mathrm{n}=5200)$. In contrast to our results, conversion to open cholecystectomy happened in $9 \% \mathrm{n}=99,601)$ of patients (10).

Concerning the postoperative outcomes, cases with gallbladder wall thickening had lengthier median hospitalization. While nonsignificant, postoperative infections were more frequent in cases with thicker gallbladder wall ${ }^{(\mathbf{1 1})}$.

In contrast to our study, Kokoroskos et al. found that severe gallbladder wall thickening $(>0.7 \mathrm{~cm})$ was non-dependently accompanying with the rate of conversions to open and general intraoperative procedures ${ }^{(11)}$.
Kaushik study reported that complications with bleeding happen at a rate at most $10 \%$. The study enrolled 10320 reports in English, and findings from 7 medical centers with more than 1000 LCs each. Kaushik revealed 2 bleedings $(0.04 \%)$ out of 4975 LCs (12).

Singh revealed that the commonest postoperative complications were bleeding from the abdomen more than $100 \mathrm{ml}$ daily (in 8 cases counting $4 \%$ ), bile leakages through the drain more than 50-100 ml daily (4 cases, counting $2 \%$ ). Lesser frequent side-effects were surgical wound infections (3 cases, or $1.5 \%$ ), incisional hernia at the site of port ( 2 cases, counting $1 \%$ ), and intraabdominal abscess resulted from remaining calculus in the abdomen ( 1 cases, counting $0.5 \%)^{(8)}$.

In the present study upon assessing factors associated with postoperative complications of laparoscopic cholecystectomy, the male gender was statistically significantly correlated with complications while a nonsignificant change was found among complications and other sociodemographic variables. A significant association was found among WBCs, total bilirubin, ALT, AST, and complications while a nonsignificant association was found among gall bladder thickness and complications.

In addition to our results, Kumar et al. demonstrated that there were 13 conversions $(6.5 \%)$, and they were commoner in men (10 male, $5 \%)$ in comparison with women (3 female, or $1.5 \%$ ). This change was as well significant ( $\mathrm{p}$ value $<0.05$ ). Furthermore, the US results of empyema, gangrene of the gallbladder wall, and elevated gallbladder wall width more than $0.3 \mathrm{~cm}$ is a significant prognosticator of complication and conversions $(\mathrm{OR}=5.17,95 \% \mathrm{CI}$ 1.69-18.39, $\mathrm{p}$ value $<0.001)^{(13) .}$

In comparing to our results, the liver function tests (LFTs) of the patients of both groups (without complications and with complications) were similar with each other. Between the investigated factors there was nonsignificant change among the total bilirubin and direct bilirubin values. But, there was a significant change in the alkaline phosphatase values, the causes for which isn't obvious ${ }^{(\mathbf{1 4})}$.

A report was focused to recognize the probable prognosticators of trouble in laparoscopic cholecystectomy. They found that ageing cases are more expected to have a hard LC. Women underwent this operation more commonly, but men lean to have a higher number of hard operations. Recurrent cholecystitis is a prognosticator. Obese cases and those with recurrent cholecystitis tend to have more intraoperative complications. Preceding operation inclines to complications in cholecystectomy ${ }^{(9)}$.

Cases who wanted preoperative ERCP had more likelihoods of having a hard cholecystectomy. Abnormal serum hepatic and pancreatic enzymes were accompanying with trouble in operation. Preoperative USG may expect complications throughout LG. Factors 
like distended or contracted gallbladder, intraperitoneal adhesion, structural irregularities or alterations and the existence of a cirrhotic liver are symptoms that are accompanying with succeeding complications throughout the operation ${ }^{(9)}$

\section{CONCLUSION}

In conclusion, this study evaluated the parameters that predict the complications in LC. Patient factors included male sex, leukocytic count, ALT and AST.

Availability of data and material: Available

Competing interests: none

Funding: No fund.

Conflicts of Interest: The author declares no conflicts of interest regarding the publication of this paper.

\section{REFERENCES}

1. Atta H, Mohamed A, Sewefy A et al. (2017): Difficult laparoscopic cholecystectomy and trainees: predictors and results in an academic teaching hospital. https://doi.org/10.1155/2017/6467814

2. Di Buono G, Romano G, Galia M et al. (2021): Difficult laparoscopic cholecystectomy and preoperative predictive factors. Sci Rep., 11(1):1-6.

3. Ahmed N, ul Hassan M, Tahira M et al. (2018): Intraoperative predictors of difficult cholecystectomy and conversion to open cholecystectomy-A new scoring system. Pakistan J Med Sci., 34(1):62.

4. Goh J, Tan J, Lim J et al. (2017): Laparoscopic cholecystectomy for acute cholecystitis: an analysis of early versus delayed cholecystectomy and predictive factors for conversion. Minerva Chir., 72(6):455-63.

5. Bouassida M, Chtourou M, Charrada H et al. (2017): The severity grading of acute cholecystitis following the
Tokyo Guidelines is the most powerful predictive factor for conversion from laparoscopic cholecystectomy to open cholecystectomy. J Visc Surg., 154(4):239-43.

6. Chand P, Kaur M, Bhandari S (2019): Preoperative predictors of level of difficulty of laparoscopic cholecystectomy. Niger J Surg Off Publ Niger Surg Res Soc., 25(2):153.

7. Kulkarni S , Kumar S (2018): Preoperative predictors of a difficult laparoscopic cholecystectomy. Int Surg J., 5(2):608-13.

8. Singh S (2020): A retrospectively predictive assessment of the various factors responsible for the difficult laparoscopic cholecystectomy. Eur J Mol Clin Med., 7(10): 4374-4383.

9. Vivek M, Augustine A, Rao $R$ (2014): A comprehensive predictive scoring method for difficult laparoscopic cholecystectomy. J Minim Access Surg., 10(2):62.

10. Murphy M, Ng S-C, Simons J et al. (2010): Predictors of major complications after laparoscopic cholecystectomy: surgeon, hospital, or patient? J Am Coll Surg., 211(1):73-80.

11. Kokoroskos $\mathrm{N}$, Peponis $\mathrm{T}$, Lee $\mathrm{J}$ et al. (2020): Gallbladder wall thickness as a predictor of intraoperative events during laparoscopic cholecystectomy: A prospective study of 1089 patients. Am J Surg., 220(4):1031-7.

12. Kaushik $R$ (2010): Bleeding complications in laparoscopic cholecystectomy: Incidence, mechanisms, prevention and management. J Minim Access Surg., 6(3):59.

13. Kumar A, Singh D, Nitesh D et al. (2021): A clinical evaluation of the predictor variables for difficult laparoscopic cholecystectomy: a prospective study. Eur J Mol Clin Med., 7(10):3680-9.

14. Atmaram D, Lakshman K. (2011): Predictive factors for conversion of laparoscopic cholecystectomy. Indian J Surg., 73(6):423-6. 